\title{
Rate Coefficients and Mechanistic Analysis for the Reaction of Hydroxyl Radicals with 1,1-Dichloroethylene and trans-1,2-Dichloroethylene over an Extended Temperature Range
}

\author{
Takahiro Yamada, Abdulaziz El-Sinawi, Masud Siraj, and Philip H. Taylor* \\ Environmental Sciences and Engineering Group, University of Dayton Research Institute, 300 College Park, \\ Dayton, Ohio 43469-0132
}

\author{
Jingping Peng, Xiaohua Hu, and Paul Marshall \\ Department of Chemistry, University of North Texas, P.O. Box 305070, Denton, Texas 76203-5070
}

Received: March 8, 2001; In Final Form: June 7, 2001

\begin{abstract}
Rate coefficients are reported for the gas-phase reaction of the hydroxyl radical $(\mathrm{OH})$ with 1,1-dichloroethylene $\left(k_{1}\right)$ and trans-1,2-dichloroethylene $\left(k_{2}\right)$ over an extended temperature range at $740 \pm 10$ Torr in a He bath gas. Absolute rate measurements were obtained using a laser photolysis/laser-induced fluorescence (LP/LIF) technique under slow flow conditions. Rate measurements for $k_{1}$ exhibited complex behavior with negative temperature dependence at temperatures below $640 \mathrm{~K}$, a rapid falloff in rate between 650 and $700 \mathrm{~K}$, and positive temperature dependence from 700 to $750 \mathrm{~K}$. The simple Arrhenius equation adequately describes the data below $640 \mathrm{~K}$ and above $700 \mathrm{~K}$ and is given (in units of $\mathrm{cm}^{3}$ molecule $\mathrm{s}^{-1}$ ) by $k_{1}(291-640 \mathrm{~K}$ ) $=$ $(1.81 \pm 0.36) \times 10^{-12} \exp (511 \pm 71) / \mathrm{T}$ and $k_{1}(700-750 \mathrm{~K})=3.13 \times 10^{-10} \exp (-5176 / T)$. Rate measurements for $k_{2}$ also exhibited complex behavior with a near-zero or slightly negative temperature dependence below $500 \mathrm{~K}$ and a near-zero or slightly positive temperature dependence above $500 \mathrm{~K}$. The modified Arrhenius equation adequately describes all of the data and is given (in units of $\mathrm{cm}^{3}$ molecule $\mathrm{s}^{-1}$ ) by $k_{2}(293-720 \mathrm{~K}$ ) $=(9.75 \pm 1.14) \times 10^{-18} T^{1.73 \pm 0.05} \exp (727 \pm 46) / T$. Error limits are $2 \sigma$ values. The room-temperature values for $k_{1}$ and $k_{2}$ are within $\pm 2 \sigma$ of previous data using different techniques. The rate measurements were modeled using QRRK theory. OH addition to the unsubstituted carbon followed by adduct stabilization describes the low-temperature measurements for $k_{1}$. Analysis of equilibration in this system yields a $\mathrm{C}-\mathrm{O}$ bond dissociation enthalpy of $32.8 \pm 1.5 \mathrm{kcal} \mathrm{mol}^{-1}$ at $298 \mathrm{~K}$, a value confirmed by ab initio calculations. $\mathrm{OH}$ addition followed by $\mathrm{Cl}$ elimination described the experimental data for $k_{2}$. Ab initio based transition state calculations for the $\mathrm{H}$ atom abstraction channel indicated that this mechanism is consistent with the rate measurements for $k_{1}$ above $700 \mathrm{~K}$. The $\mathrm{H}$ abstraction channel for $k_{2}$ could not be observed because of the presence of a more rapid $\mathrm{Cl}$ elimination channel at elevated temperatures. $\mathrm{H}$ abstraction is predicted to be the dominant reaction channel for both $k_{1}$ and $k_{2}$ at flame temperatures.
\end{abstract}

\section{Introduction}

The dichloroethylenes represent significant organochlorine emissions to the environment. Vinylidene chloride $\left(1,1-\mathrm{C}_{2} \mathrm{H}_{2}-\right.$ $\mathrm{Cl}_{2}$ ) is used industrially for the production of poly(vinyl dichloroethylene) (PVDC) and 1,1,1-trichloroethane and was produced at a worldwide rate of 200000 metric tons in $1985 .{ }^{1}$ Vinylidene chloride is classified as a possible human carcinogen by the Integrated Risk Information System of the EPA. ${ }^{2} 1,2-$ dichloroethylene is of little industrial importance but is nonetheless significant environmentally because it is a byproduct of chloroethylene manufacture. ${ }^{1}$ High-temperature incineration remains the best available technology for the complete and permanent disposal of these hazardous materials. An important process contributing to the initial destruction of halogenated hydrocarbons under both atmospheric and combustion conditions is reaction with $\mathrm{OH}$ radicals. . $^{3,4}$

Previous measurements of the reaction of $\mathrm{OH}$ with 1,1- and 1,2-dichloroethylene were limited to low temperatures (220$432 \mathrm{~K}) .^{1,5-8}$ Arrhenius parameters derived from the previous

* To whom correspondence should be addressed. Fax: (937) 229-2503, e-mail: taylorph@udri.udayton.edu.

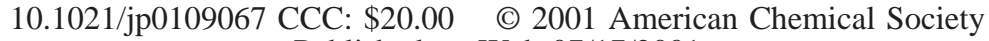

TABLE 1: Arrhenius Parameters from Previous Rate Measurements - 1,1-Dichloroethylene

\begin{tabular}{ccccc}
\hline $\left.\begin{array}{c}10^{12} \times \mathrm{A} \\
\left(\mathrm{cm}^{3} \text { molecule }\right.\end{array} \mathrm{s}^{-1}\right)$ & $E_{\mathrm{a}}\left(\mathrm{cal} \mathrm{mol}^{-1}\right)$ & $T(\mathrm{~K})$ & technique & ref \\
\hline $2.30 \pm 0.44$ & $-938 \pm 209$ & $240-400$ & FP-RF & 7 \\
$1.6 \pm 0.6$ & $-1113 \pm 219$ & $297-368$ & DF-LIF & 8 \\
$0.225 \pm 0.027$ & $-2271 \pm 95.6$ & $298-432$ & DF-MS & 1
\end{tabular}

TABLE 2: Arrhenius Parameters from Previous Rate Measurements - 1,2-Dichloroethylene

$10^{12} \times \mathrm{A}$

\begin{tabular}{|c|c|c|c|}
\hline$\left(\mathrm{cm}^{3}\right.$ molecule $\left.{ }^{-1} \mathrm{~s}^{-1}\right)$ & $E_{\mathrm{a}}\left(\mathrm{cal} \mathrm{mol}^{-1}\right)$ & $T(\mathrm{~K})$ & technique \\
\hline & $-562 \pm 1$ & $240-4$ & $\mathrm{FP}-\mathrm{l}$ \\
\hline $2.1 \pm 0.8$ & $-40 \pm 238$ & $297-367$ & DF-LIF \\
\hline
\end{tabular}

studies are summarized in Tables 1 and 2 for 1,1-dichloroethylene and 1,2-dichloroethylene, respectively.

The reaction mechanism is presumed to be addition to the $\pi$ electrons associated with the $\mathrm{C}=\mathrm{C}$ double bond. Edney et al. ${ }^{5}$ measured the room-temperature rate constant for $\mathrm{OH}$ reaction with vinylidene chloride using the relative rate method. The rate constant observed $\left(14.9 \times 10^{-12} \mathrm{~cm}^{3}\right.$ molecule $\left.{ }^{-1} \mathrm{~s}^{-1}\right)$ appeared to be anomalously high compared to reported values 
for the other chloroethylenes $\left(0.2-8.1 \times 10^{-12} \mathrm{~cm}^{3}\right.$ molecule ${ }^{-1}$ $\left.\mathrm{s}^{-1}\right){ }^{9}$ Using a similar experimental approach, Tuazon et al. ${ }^{6}$ examined the room-temperature rate constant for $\mathrm{OH}$ reaction with 1,1- and 1,2-dichloroethylenes. However, in these studies, experiments were performed with and without a $\mathrm{Cl}$ atom scavenger (ethane). Plots of 1,1- and 1,2-dichloroethylene versus dimethyl ether (reference compound) consumption indicated that secondary processes contributed to substrate loss. As a result, the $\mathrm{OH}$ rate constants were obtained using the $\mathrm{Cl}$ atom scavenger and rates of 8.11 and $1.80 \times 10^{-12} \mathrm{~cm}^{3}$ molecule ${ }^{-1} \mathrm{~s}^{-1}$ were observed for 1,1- and trans-1,2-dichloroethylene, respectively. Product analyses using FTIR spectroscopy confirmed that secondary reaction chemistry involving $\mathrm{Cl}$ atoms was important for both substrates.

Kirchner et al. ${ }^{1}$ measured the kinetics and reaction products from $\mathrm{OH}$ reactions with 1,1-dichloroethylene at low temperatures $(298-432 \mathrm{~K})$ and pressures of $\sim 1$ Torr using electron impact mass spectrometry. The observed product distributions were complex and indicated that $\mathrm{Cl}$ elimination was insignificant. The mass spectral ions were furthermore indicative of a reaction mechanism involving primarily $\mathrm{OH}$ addition to the $\mathrm{CH}_{2}$ side of the substrate. This is consistent with the absence of $\mathrm{Cl}$ elimination, which is only expected when the $\mathrm{OH}$ radical attacks the $\mathrm{CCl}_{2}$ side or migrates there from the $\mathrm{CH}_{2}$ side. Zhang et al. ${ }^{7}$ measured the kinetics of the reaction of $\mathrm{OH}$ radicals with 1,1- and 1,2-dichloroethylene from 240 to $400 \mathrm{~K}$ using the flash photolysis-resonance fluorescence technique. The reactions were observed to be independent of pressure over a range of 5-50 Torr of argon. Their rate measurements for the dichloroethylenes (11.2 and $2.50 \times 10^{-12} \mathrm{~cm}^{3}$ molecule ${ }^{-1} \mathrm{~s}^{-1}$ for 1,1and trans-1,2-dichloroethylene, respectively) compared to that of ethylene $\left(8.06 \times 10^{-12} \mathrm{~cm}^{3} \text { molecule } \mathrm{e}^{-1} \mathrm{~s}^{-1}\right)^{9}$ indicated that the chlorine atom deactivates the carbon on which it is attached toward $\mathrm{OH}$ attack while activating the carbon on the other side of the double bond. Abbatt and Anderson ${ }^{8}$ measured the kinetics of the reaction $\mathrm{OH}$ radicals with 1,1- and 1,2-dichloroethylene from 297 to $367 \mathrm{~K}$ using the discharge flow method coupled with laser-induced fluorescence detection. The reactivity of the chloroethylenes was observed to be considerably less than that of unsubstituted olefinic hydrocarbons when considered in terms of the alkenes ionization potentials. This was rationalized in terms of molecular orbital theory and the fact that the highest occupied molecular orbital is composed of carbon-carbon $\pi$ bonding and halogen atom lone-pair contributions. The attacking $\mathrm{OH}$ radical experiences greater nonbonding interactions in the transition state than it does in the $\mathrm{OH} /$ alkene reactions, where the HOMO is solely carbon-carbon $\pi$ bonding.

Given the lack of available data above $430 \mathrm{~K}$, knowledge of the reaction rate constants and reaction mechanisms over an extended temperature range is essential to accurately predicting the combustion behavior of these compounds. Of specific interest to the dichloroethylenes is the relative importance of adduct stabilization, $\mathrm{Cl}$ elimination, and $\mathrm{H}$ abstraction. In this manuscript, we present absolute rate coefficients for the reaction of $\mathrm{OH}$ with $1,1-\mathrm{C}_{2} \mathrm{H}_{2} \mathrm{Cl}_{2}\left(k_{1}\right)$ and 1,2- $\mathrm{C}_{2} \mathrm{H}_{2} \mathrm{Cl}_{2}\left(k_{2}\right)$ at atmospheric pressure over an extended temperature range:

$$
\begin{aligned}
& 1,1-\mathrm{C}_{2} \mathrm{H}_{2} \mathrm{Cl}_{2}+\mathrm{OH} \rightarrow \text { products } \\
& 1,2-\mathrm{C}_{2} \mathrm{H}_{2} \mathrm{Cl}_{2}+\mathrm{OH} \rightarrow \text { products }
\end{aligned}
$$

Arrhenius parameters are derived from the data. A comparison of these measurements with prior measurements at lower temperatures and pressures is discussed. Ab initio calculations were performed to estimate thermodynamic properties, enthal- pies of formation, entropies, and heat capacities. QRRK calculations were also performed to calculate energy dependent rate constants, $k(E)$, using the above thermodynamic properties. The most likely reaction mechanisms based on the ab initio and QRRK modeling of these reaction systems and their consistency with the available experimental data are discussed.

\section{Experimental Approach and Data Reduction}

The experimental procedures developed for LP-LIF studies of the reaction of $\mathrm{OH}$ radicals with chloroethylenes have been previously published. ${ }^{10-12} \mathrm{~A}$ brief summary is given in the following paragraphs.

To minimize substrate photolysis at wavelengths $<300 \mathrm{~nm}$, HONO was used as a hydroxyl radical source. Parts per million concentrations of pure HONO $(>99 \%)$ were generated as described by Febo et al. ${ }^{13}$ and Brust et al. ${ }^{14}$ HONO dissociates primarily into $\mathrm{NO}$ and $\mathrm{OH}$ when exposed to near-UV radiation of $351 \mathrm{~nm}$. A competing dissociation channel, production of $\mathrm{NO}_{2}$ and $\mathrm{H}$ atoms, has been observed to be negligible under similar experimental conditions. ${ }^{15}$ A XeF excimer laser (Lamba Physik Compex model 102) was used as the photodissociation source. Initial $[\mathrm{OH}]_{0}$ ranged from $\sim 3 \times 10^{10}$ to $9 \times 10^{10}$ molecules $\mathrm{cm}^{-3}$ and was determined based on the measured excimer fluence $\left(9-18 \mathrm{~mJ} \mathrm{~cm}^{-2}\right)$, the most recent published value of the absorption cross-section for HONO, $1.54 \times 10^{-19}$ $\mathrm{cm}^{2} /$ molecule at $351 \mathrm{~nm},{ }^{14}$ a quantum yield of unity, ${ }^{16}$ and measured values of $\left[\mathrm{NO}_{2}^{-}\right]$taken to represent [HONO] determined using ion chromatography $\left[\sim(1-3) \times 10^{13}\right.$ molecules $\left.\mathrm{cm}^{-3}\right]$.

Initial substrate concentrations in the reactor, based on measured flow rates, ranged from $\sim 3 \times 10^{13}$ to $\sim 1 \times 10^{15}$ molecules $\mathrm{cm}^{-3}$. The absence of adsorption on the injector probe (coated with boric acid) and reactor walls was verified using GC/MS analysis. All experiments were conducted at a total pressure of $740 \pm 15$ Torr. Samples of 1,1- and 1,2-dichloroethylene (99.9\% purity) were obtained from Aldrich. GC/MS analyses indicated that this purity was met or exceeded.

The rate of disappearance of the $\mathrm{OH}$ may be presented as

$$
-\mathrm{d}[\mathrm{OH}] / \mathrm{dt}=k\left[A_{0}\right][\mathrm{OH}]+k_{\mathrm{d}}[\mathrm{OH}]
$$

where $k=$ bimolecular rate constant, $A_{0}=$ substrate concentration, and $k_{\mathrm{d}}=$ first-order rate for the reaction of $\mathrm{OH}$ with $\mathrm{HONO}$ and also includes diffusion out of the reaction volume. This relationship holds in the absence of any secondary reactions that may form or deplete $\mathrm{OH}$. Solution of this equation yields $[\mathrm{OH}]=[\mathrm{OH}]_{0}$ exp $-\left(k^{\prime} t\right)$, where $k^{\prime}=k+k_{\mathrm{d}}$. For all experiments, reactive and diffusive $\mathrm{OH}$ radical decay profiles exhibited exponential behavior and were fitted by the following nonlinear expression:

$$
[\mathrm{OH}]=[\mathrm{OH}]_{0} \exp -\left(k^{\prime} \mathrm{t}\right)+\gamma
$$

where $\gamma$ is the constant background signal level and $t$ is the time delay between the laser pulses. Because the organic concentration was much greater than the $[\mathrm{OH}]$, pseudo firstorder exponential $\mathrm{OH}$ decays were observed and the individual temperature-dependent rate constants were determined by $k^{\prime}=$ $k$ [substrate] $+k_{\mathrm{d}}$, where the bimolecular rate constant, $k$, is the slope of the least-squares fit of $k^{\prime}$ versus the organic concentration. $\mathrm{OH}$ decays were measured over two to three decay lifetimes over a time interval of $0.2-30.0 \mathrm{~ms}$. Values of $k_{\mathrm{d}}$ measured before and after a rate determination were observed to be constant within experimental uncertainties, indicating that the HONO source was stable over the course of an experiment. 


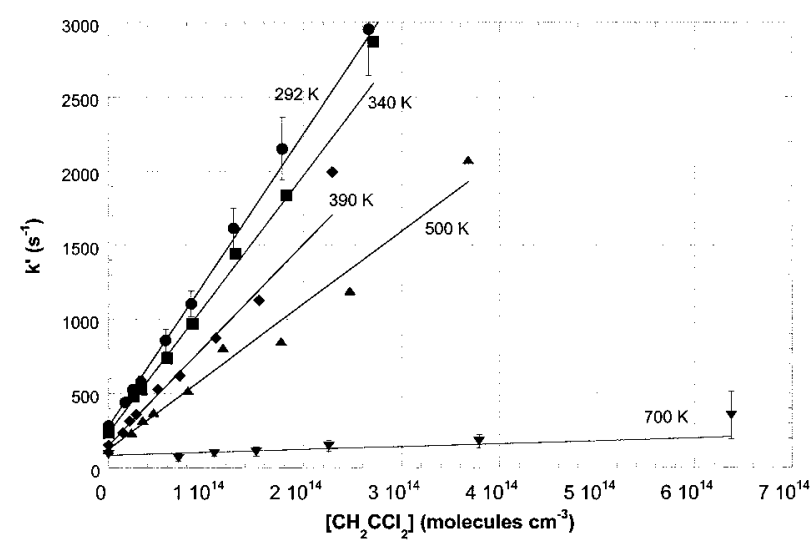

Figure 1. Plot of pseudo-first-order rate constants versus concentration for $\mathrm{CH}_{2} \mathrm{CCl}_{2}$ at five different reaction temperatures. Error bars for the 292 and $740 \mathrm{~K}$ data denote $\pm 2 \sigma$ random error limits.

TABLE 3: Absolute Rate Coefficients $\left(k_{1}\right)$ for $\mathbf{O H}+$ $\mathrm{CH}_{2}=\mathrm{CCl}_{2}$

\begin{tabular}{cccc}
\hline$T(\mathrm{~K})$ & $\begin{array}{c}10^{12} k_{1} \\
\left(\mathrm{~cm}^{3} \text { molecule }^{-1} \mathrm{~s}^{-1}\right)\end{array}$ & $T(\mathrm{~K})$ & $\left.\begin{array}{c}10^{12} k_{1} \\
\left(\mathrm{~cm}^{3} \text { molecule }\right.\end{array} \mathrm{s}^{-1}\right)$ \\
\hline 291 & $10.01 \pm 1.00^{a}$ & 550 & $4.45 \pm 0.43$ \\
292 & $9.84 \pm 0.37$ & 600 & $3.96 \pm 0.60$ \\
340 & $8.71 \pm 0.37$ & 640 & $4.14 \pm 0.78$ \\
378 & $6.65 \pm 0.86$ & $680^{b}$ & $0.80 \pm 0.38$ \\
383 & $6.67 \pm 0.77$ & 700 & $0.19 \pm 0.02$ \\
390 & $6.80 \pm 0.62$ & 720 & $0.23 \pm 0.03$ \\
440 & $5.70 \pm 0.81$ & 750 & $0.37 \pm 0.13$ \\
500 & $4.90 \pm 0.54$ & &
\end{tabular}

${ }^{a}$ Errors represent $\pm 2 \sigma$ and do not include the 5-10\% uncertainty estimated for possible systematic errors. ${ }^{b} \mathrm{OH}$ decays at low substrate concentration exhibited biexponential character.

Numerical modeling indicated that the dominant source of $\mathrm{OH}$ decay in the absence of the substrate was the reaction with HONO $\left(k_{298}=4.5 \times 10^{-12} \mathrm{~cm}^{3}\right.$ molecule $\left.{ }^{-1} \mathrm{~s}^{-1}\right) \cdot{ }^{15}$ Typical values of $k_{\mathrm{d}}$ decreased from $\sim 250 \mathrm{~s}^{-1}$ at low temperatures to $\sim 100 \mathrm{~s}^{-1}$ at elevated temperatures, suggesting a reduction in the gas-phase concentration of HONO with increasing temperature. A plot of $k^{\prime}$ versus substrate concentration for 1,1dichloroethylene at selected temperatures is shown in Figure 1.

\section{Experimental Results}

Rate data for $k_{1}$ and $k_{2}$ were obtained from ambient temperatures to $\sim 750 \mathrm{~K}$, under atmospheric pressure conditions. $\mathrm{OH}$ signals generated from the photolysis of HONO decreased below acceptable levels $(\mathrm{S} / \mathrm{N}$ ratio $<10)$ at higher temperatures, indicating significant thermal decomposition of HONO. The reduction in photolytically generated $\mathrm{OH}$ above $750 \mathrm{~K}$ was accompanied by an increase in background LIF, apparently because of the thermal generation of $\mathrm{OH}$ from the decomposition of HONO. Sources of secondary chemistry were not evident on the basis of chemical analysis of the gas stream containing the HONO precursors. ${ }^{10}$ Concentrations of $\mathrm{NO}, \mathrm{NO}_{2}$, and $\mathrm{HCl}$ were below detection limits $\left(<1.2 \times 10^{12}\right.$ molecules $\left.\mathrm{cm}^{-3}\right)$. The $\mathrm{OH}$ consumption rate was thus controlled by the initial HONO concentration, which was maintained below $5 \times 10^{13}$ molecules $\mathrm{cm}^{-3}$ to limit the first-order $\mathrm{OH}$ decay rate to $<300 \mathrm{~s}^{-1}$.

Absolute rate coefficients for $k_{1}$ and $k_{2}$ are presented in Tables 3 and 4 , respectively. Random error limits $( \pm 2 \sigma)$ were below $15 \%$ at most temperatures. Rate measurements were collected for a wide range of initial concentrations and included an order of magnitude concentration difference for each series of runs. Substrate partial pressures were measured with a capacitance manometer. Substrate concentrations were based on total flow
TABLE 4: Absolute Rate Coefficients $\left(k_{2}\right)$ for $\mathbf{O H}+$ trans $-\mathrm{CHCl}=\mathbf{C H C l}$

\begin{tabular}{cccc}
\hline$T(\mathrm{~K})$ & $\left.\begin{array}{c}10^{12} k_{2} \\
\left(\mathrm{~cm}^{3} \text { molecule }\right.\end{array} \mathrm{s}^{-1}\right)$ & $T(\mathrm{~K})$ & $\left(\mathrm{cm}^{3}\right.$ molecule $\left.{ }^{-1} \mathrm{~s}^{-1}\right)$ \\
\hline 293 & $2.24 \pm 0.31^{a}$ & 610 & $2.08 \pm 0.31$ \\
330 & $2.07 \pm 0.27$ & 650 & $2.17 \pm 0.24$ \\
340 & $1.95 \pm 0.13$ & 660 & $2.31 \pm 0.21$ \\
380 & $2.14 \pm 0.18$ & 700 & $2.33 \pm 0.24$ \\
440 & $1.87 \pm 0.19$ & 720 & $2.32 \pm 0.39$ \\
530 & $2.02 \pm 0.24$ & &
\end{tabular}

${ }^{a}$ Errors represent $\pm 2 \sigma$ and do not include the 5-10\% uncertainty estimated for possible systematic errors.

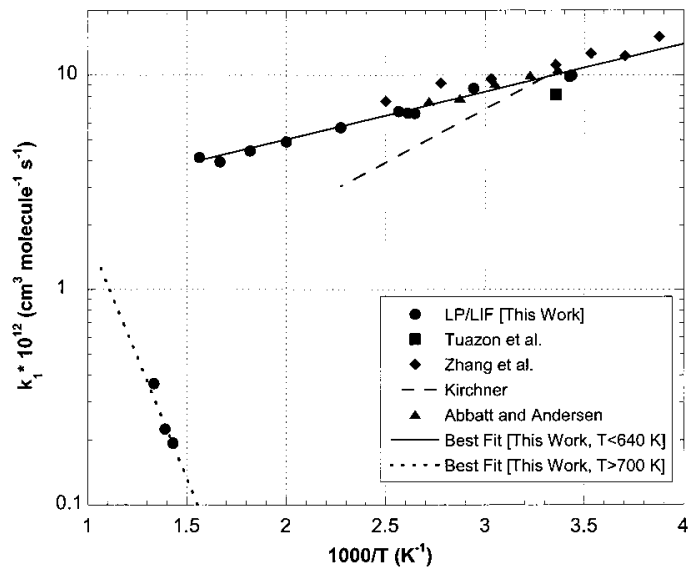

Figure 2. Arrhenius plot of kinetic data for $k_{1}$. Also shown are the results of previous studies (Tuazon et al.: $p=1 \mathrm{~atm}$; bath gas, $80 \%$ $\mathrm{N}_{2}$ and $20 \% \mathrm{O}_{2}$. Kirchner et al.: $p=1-3$ Torr; bath gas, He. Abbatt and Anderson: $p=55-85$ Torr; bath gas, $\mathrm{N}_{2}$. Zhang et al.: $p=35$ Torr; bath gas, Ar) and an Arrhenius fit to the data from this study (291-640 K and 700-750 K, $p=740 \pm 10$ Torr).

measurements checked before and after each rate measurement using the soap bubble method.

All known rate measurements for $k_{1}$ are summarized in Figure 2. This work extends experimental measurement beyond the limit of $\sim 400 \mathrm{~K}$ reported previously. A variety of techniques were used to collect these data. Examination of Figure 2 shows agreement at room temperature, within combined experimental uncertainties, between our work and that reported previously. ${ }^{1,6-8}$ Rate measurements for $k_{1}$ exhibited complex behavior with negative temperature dependence at temperatures below $640 \mathrm{~K}$, a rapid falloff in rate between 640 and $700 \mathrm{~K}$, and an increase in rate above $700 \mathrm{~K}$.

The simple Arrhenius equation adequately describes the data below $640 \mathrm{~K}$ and above $700 \mathrm{~K}$, and is given (in units of $\mathrm{cm}^{3}$ molecule ${ }^{-1} \mathrm{~s}^{-1}$ ) by

$$
\begin{aligned}
& k_{1}(291-640 \mathrm{~K})=(1.81 \pm 0.36) \times \\
& 10^{-12} \exp (511.3 \pm 71.0) / T \\
& k_{1}(700-750 \mathrm{~K})=3.13 \times 10^{-10} \exp (-5176 / T)
\end{aligned}
$$

Error limits for the low-temperature data are $2 \sigma$ values. There is insufficient high-temperature data to calculate meaningful error limits. The negative activation energy derived from the Arrhenius fit to the data below $650 \mathrm{~K}$ is in good agreement with the previous studies of Zhang et al. ${ }^{7}$ and Abbatt and Andersen $^{8}\left(<0.3 \mathrm{kcal} \mathrm{mol}^{-1}\right.$ deviation). However, there is some discrepancy between our measurements and those of Kirchner et al. ${ }^{1}\left(\sim 1.7 \mathrm{kcal} \mathrm{mol}^{-1}\right.$ deviation). It is possible that in the low-pressure measurements of Kirchner et al., ${ }^{1}$ rate measure- 


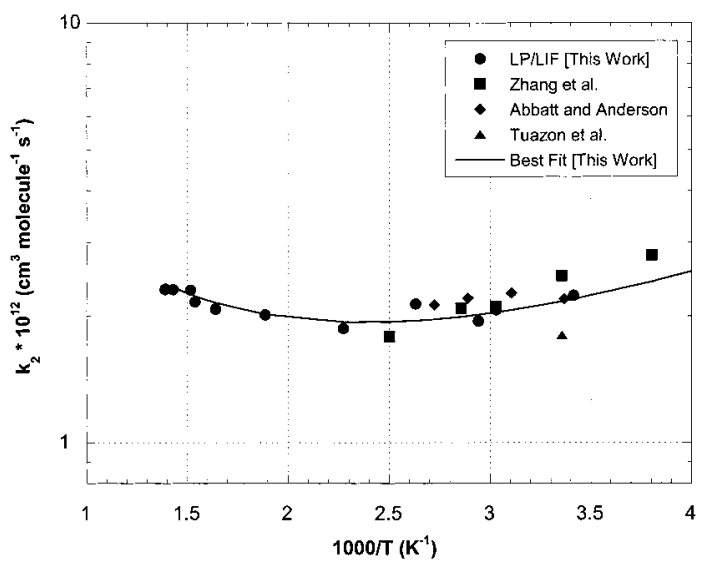

Figure 3. Arrhenius plot of kinetic data for $k_{2}$. Also shown are the results of previous studies (Tuazon et al.: $p=1 \mathrm{~atm}$; bath gas, $80 \%$ $\mathrm{N}_{2}$ and 20\% $\mathrm{O}_{2}$. Abbatt and Anderson: $p=55-85$ Torr; bath gas, $\mathrm{N}_{2}$. Zhang et al.: $p=35$ Torr; bath gas, Ar) and a three-parameter modified Arrhenius fit to the data from this study $(293-720 \mathrm{~K}, p=740 \pm 10$ Torr).

ments for $k_{1}$ were obtained under pressure falloff conditions (see the Modeling Results section).

All known rate measurements for $k_{2}$ are summarized in Figure 3. This work extends experimental measurements beyond the limit of $\sim 400 \mathrm{~K}$ reported previously. Examination of Figure 3 shows excellent agreement at room temperature $( \pm 10 \%)$ between our results and those reported previously by Zhang et al. ${ }^{7}$ and Abbatt and Anderson. ${ }^{8}$ The previous room-temperature rate measurements of Tuazon et al. ${ }^{6}$ using the relative rate method were $\sim 18 \%$ lower than our measurements. Rate measurements for $k_{2}$ exhibited a slightly negative or near-zero temperature dependence below $500 \mathrm{~K}$ and a slightly positive or near-zero temperature dependence above $500 \mathrm{~K}$. The modified Arrhenius equation yielded a better fit to the data than the simple Arrhenius expression and is given (in units of $\mathrm{cm}^{3}$ molecule ${ }^{-1}$ $\left.\mathrm{s}^{-1}\right)$ by

$$
\begin{aligned}
k_{2}(293-720 \mathrm{~K})=(9.75 \pm & 1.14) \times \\
& 10^{-18} T^{1.73 \pm 0.05} \exp (727 \pm 46) / T
\end{aligned}
$$

Error limits are $2 \sigma$ values. The near-zero activation energy below $400 \mathrm{~K}$ is in good agreement with the previous studies of Abbatt and Andersen ${ }^{8}$ (see Figure 3). Zhang et al. ${ }^{7}$ reported a larger negative activation energy of $\sim 0.6 \mathrm{kcal} \mathrm{mol}^{-1}$. However, the respective temperature dependencies of the study of Zhang et al. ${ }^{7}$ and this study are statistically identical between 298 and $400 \mathrm{~K}$.

\section{Theoretical Approach}

The composite ab initio calculation method, G3(MP2), ${ }^{17}$ was used to calculate thermodynamic properties of reactants, intermediate radicals, transition states (TSs), and products with the Gaussian $94^{18}$ and Gaussian $98^{19}$ computer codes. The enthalpies of formation of the reactants were obtained from the literature. ${ }^{20-22}$ The enthalpies of formation of intermediate radicals, TSs, and products were determined by the energy differences from the reactants, calculated by G3(MP2). ${ }^{17} \mathrm{ZPE}$ and thermal correction were incorporated to estimate enthalpies of formation at 298 K. ${ }^{23}$ Entropy and heat capacity were calculated based on the geometry optimized with MP2(full)/6-31G(d), and frequencies were calculated with the HF/6-31G(d) level of theory using statistical mechanics. The internal rotational motions were treated as hindered rotors using the internal rotational treatment advanced by Pitzer and Gwinn. ${ }^{24}$

The rate coefficients for each pathway can be expressed, in general terms, using transition state theory $(\mathrm{TST})^{25}$ as shown below:

$$
k=\left(k_{\mathrm{b}} T / h\right) \exp \left(\Delta S^{\ddagger} / R\right) \exp \left(-\Delta H^{\ddagger} / R T\right)
$$

where $h$ is Planck's constant, $k_{b}$ is the Boltzmann constant, and

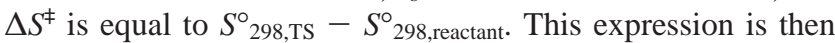
fitted by three parameters, $B, n$, and $C$, over a temperature range of $200-2000 \mathrm{~K}$, as expressed below:

$$
k=B(T)^{n} \exp (-C / R T)
$$

QRRK analyses 26,27 for $k(E)$, combined with the modified $\beta$ collision analysis of Gilbert et al., ${ }^{28}$ were used to predict the pressure-dependent rate constants.

Variational transition state theory (VTST) calculations were performed to estimate the rate constant for $\mathrm{OH}$ addition to 1,1and trans-1,2-dichloroethylene at the high-pressure limit. The calculations were carried out as follows. First, the intrinsic reaction coordinates (IRCs) for the addition of $\mathrm{OH}$ to each end of the $\mathrm{C}=\mathrm{C}$ bond were defined at the HF/6-31G(d,p) level near the saddle point region. At various fixed $\mathrm{C}-\mathrm{O}$ separations along the IRCs, frequencies were obtained normal to the IRC, also at the HF/6-31G(d,p) level of theory. The results were scaled by a factor of about 0.9. (A factor of 0.901 was employed, derived from scaling to match observed frequencies for $\mathrm{C}_{2} \mathrm{H}_{4}, \mathrm{C}_{2} \mathrm{Cl}_{4}$, and $\mathrm{OH}^{21}{ }^{21}$ ) Then energies were computed at the spin-projected PMP4/6-311+G(d,p) level, relative to reactants. ${ }^{18}$ These energies, geometries and frequencies were used to derive canonical TST rate constants as a function of position along the IRC. At each temperature, the VTST result was obtained by interpolation to find the minimum rate constant, i.e., the point where the Gibbs energy of activation is maximized.

These VTST results correspond to the high-pressure limit for $\mathrm{OH}$ addition, where the initially formed excited adduct is always stabilized by collisions. At finite pressures, some fraction of the excited adducts can dissociate back to reactants before collisional stabilization or fragmentation, and thus, the observed rate constant is likely to be smaller than the calculated one. At a given pressure, this effect will become more pronounced at elevated temperatures, because the reaction moves further from the high-pressure limit.

The variationally located transition states lie at $\mathrm{C}-\mathrm{O}$ separations approximately $0.05 \AA$ smaller than the local energy maxima along the IRCs. As may be seen from Figure 4 (top) for 1,1-dichloroethylene, the variational TS for $\beta$ addition lies in a region approximately $2 \mathrm{kcal} \mathrm{mol}^{-1}$ below the reactants' energy, whereas $\alpha$ addition (at the $\mathrm{CCl}_{2}$ end) requires overcoming a positive barrier of around $+2 \mathrm{kcal} \mathrm{mol}^{-1}$. The $\alpha$ addition channel is also found to be somewhat less favorable in an entropy context as well (the preexponential factor $\left(B T^{n} \mathrm{e}^{n}\right)$ is approximately 9 times smaller at $298 \mathrm{~K}$, see Table 5). Figure 4 (bottom) shows the reaction path for $\mathrm{OH}$ addition to trans-1,2dichloroethylene and indicates a significant computed barrier which is discussed in the following section.

The derived VTST rate constants are plotted in Figure 5. For 1,1-dichloroethylene, the $\alpha$ channel has a simple positive temperature dependence. The $\beta$ channel is more important at all temperatures and has a more complex behavior. The negative relative transition state energy contributes to a negative temperature dependence for the rate constant, an effect which dominates at low temperatures, whereas increases in temperature 

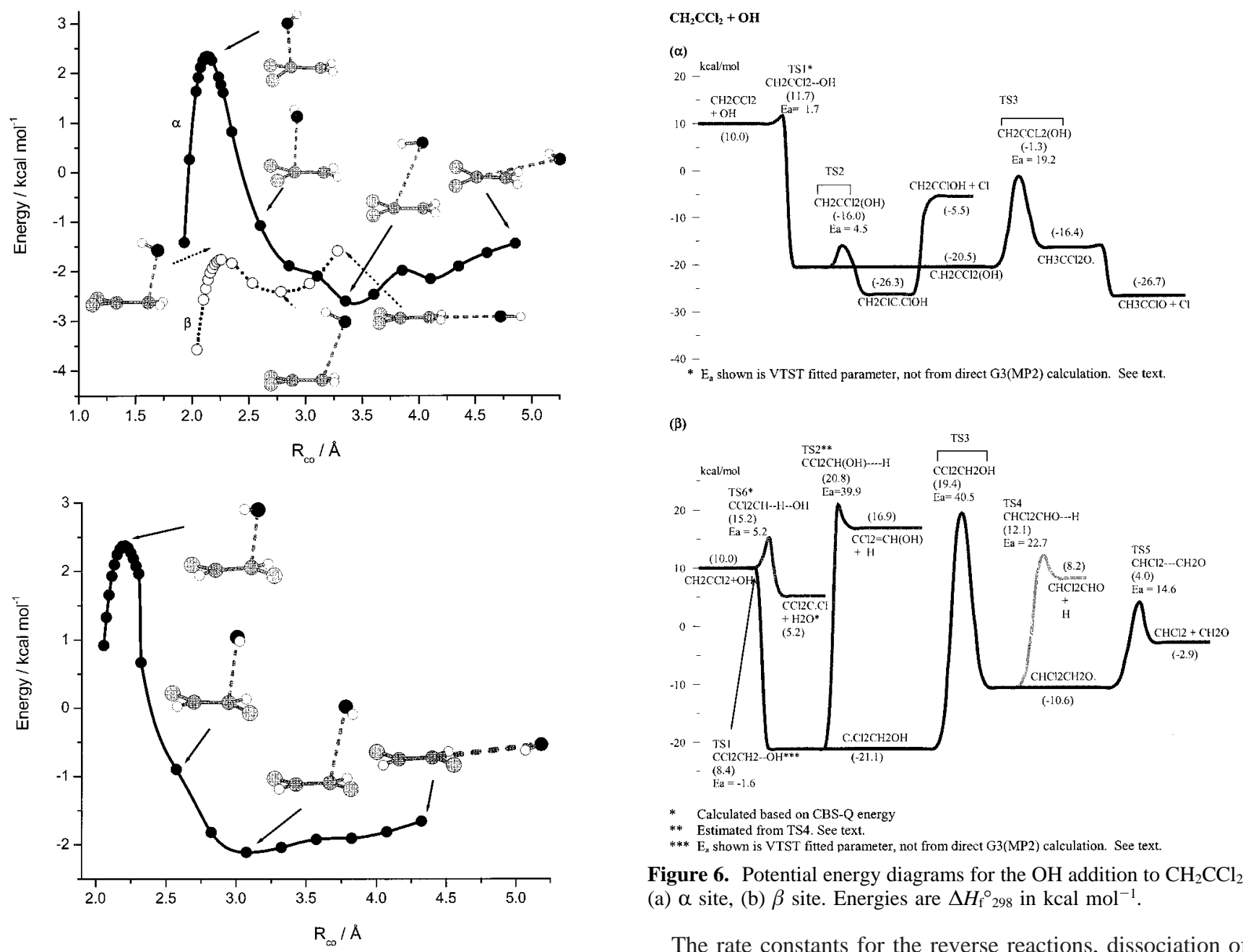

Figure 6. Potential energy diagrams for the $\mathrm{OH}$ addition to $\mathrm{CH}_{2} \mathrm{CCl}_{2}$. (a) $\alpha$ site, (b) $\beta$ site. Energies are $\Delta H_{\mathrm{f}}{ }^{\circ} 298$ in kcal mol ${ }^{-1}$.

The rate constants for the reverse reactions, dissociation of

Figure 4. (top) Classical energies (no $\mathrm{ZPE}$ ) relative to $\mathrm{OH}+\mathrm{CH}_{2-}$ $\mathrm{CCl}_{2}$ for addition of $\mathrm{OH}$ at the $\mathrm{CH}_{2}$ end ( $\beta$ site, open circles) and the $\mathrm{CCl}_{2}$ end ( $\alpha$ site, solid circles), calculated at the PMP4/6-311+G(d,p)// $\mathrm{HF} / 6-31 \mathrm{G}(\mathrm{d}, \mathrm{p})$ level of theory, together with molecular structures along the reaction path. (bottom) Classical energies (no ZPE) relative to $\mathrm{OH}$ + trans- $\mathrm{CHClCHCl}$ for addition of $\mathrm{OH}$, calculated at the PMP4/6$311+\mathrm{G}(\mathrm{d}, \mathrm{p}) / / \mathrm{HF} / 6-31 \mathrm{G}(\mathrm{d}, \mathrm{p})$ level of theory, together with molecular structures along the reaction path.

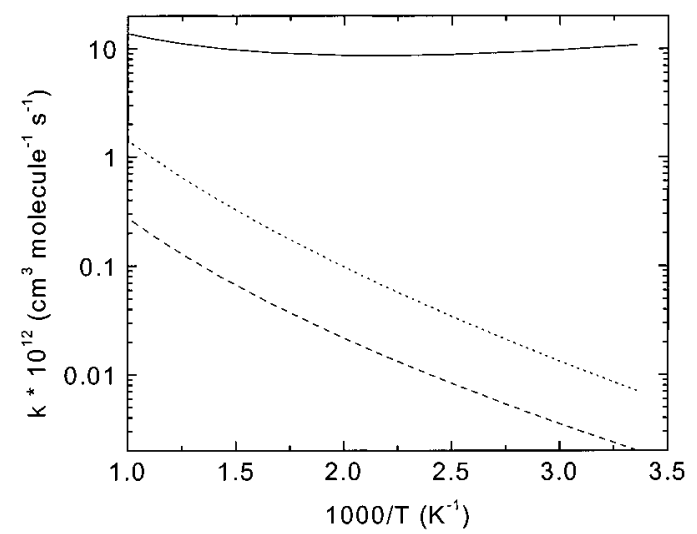

Figure 5. $\mathrm{Ab}$ initio high-pressure limit rate constants for the addition of $\mathrm{OH}$ to chlorinated ethylenes: solid line, $\mathrm{OH}+\mathrm{CH}_{2} \mathrm{CCl}_{2}$ ( $\alpha$ channel); dashed line, $\mathrm{OH}+\mathrm{CH}_{2} \mathrm{CCl}_{2}$ ( $\beta$ channel); dotted line, $\mathrm{OH}+$ trans$\mathrm{CHClCHCl}$ (see text). $\mathrm{OH}$ torsion about the forming $\mathrm{C}-\mathrm{O}$ bond was treated as a vibrator.

more rapidly increase the partition function of the loose TS as compared to the reactants, leading to increasing rate constants at higher temperatures. forward rate using the principle of microscopic reversibility.

\section{Modeling Results}

Thermodynamic properties of reactants, intermediate radicals, and TSs estimated based on G3(MP2) calculation results are given in Table 5. The activation energies for $\mathrm{H}$ atom abstraction reactions were calculated using both G3(MP2) and CBS-Q composite $\mathrm{ab}$ initio theory. ${ }^{29}$ The activation energies for $\mathrm{H}$ atom abstraction reactions using G3(MP2) were 8.69 and $6.92 \mathrm{kcal} /$ mol at $0 \mathrm{~K}$ for 1,1- and 1,2-dichloroethylene, respectively, whereas the CBS-Q calculation yielded values of 5.36 and 3.78 $\mathrm{kcal} / \mathrm{mol}$ at $0 \mathrm{~K}$ for 1,1- and 1,2-dichloroethylene, respectively. The CBS-Q value was considered more accurate based on its consistency with the high-temperature 1,1-dichloroethylene data. G3(MP2) calculation results for all compounds which are involved in the reaction path analysis are given in Table 6 . CBS-Q calculation results for the $\mathrm{H}$ atom abstraction reactions are also shown in Table 6.

Figures 6 and 7 present potential energy diagrams at $298 \mathrm{~K}$ for 1,1- and 1,2-dichloroethylene, respectively. Energy levels shown are based on G3(MP2) calculation results with the exception of the entrance channels, the $\mathrm{H}$ atom abstraction channels, and $\mathrm{H}$ atom dissociation to form $\mathrm{CCl}_{2}=\mathrm{CHOH}$ (TS2 in Figure 6b). Because the TS2 energy level was calculated to be $0.7 \mathrm{kcal} \mathrm{mol}^{-1}$ lower than the product energy level, the activation energy obtained for an analogous reaction, i.e., the reverse of TS4 in Figure $6 \mathrm{~b}\left(3.9 \mathrm{kcal} \mathrm{mol}^{-1}\right)$, was applied to TS2 and the energy level was thus estimated to be $20.8 \mathrm{kcal}$ $\mathrm{mol}^{-1}$. The entrance channel is based on the VTST calculation 
TABLE 5: Thermodynamic Properties of Reactants, Intermediate Radicals, and TSs for the $\mathrm{CH}_{2}=\mathrm{CCl}_{2}+\mathrm{OH}_{\text {and }}$ $\mathrm{CHCl}=\mathrm{CHCl}+\mathrm{OH}$ Reaction System

\begin{tabular}{|c|c|c|c|c|c|c|c|c|c|c|c|}
\hline & $\Delta H_{0}^{\mathrm{f}_{0} a}$ & $S(298)^{b}$ & $\mathrm{Cp}(300)^{c}$ & $\mathrm{Cp}(400)$ & $\mathrm{Cp}(500)$ & $\mathrm{Cp}(600)$ & $\mathrm{Cp}(800)$ & $\mathrm{Cp}(1000)$ & $\mathrm{Cp}(1500)$ & symmetry $^{d}$ & source \\
\hline \multicolumn{12}{|c|}{$\begin{array}{l}\mathrm{CH}_{2} \mathrm{CCl}_{2}+\mathrm{OH} \\
\text { Alpha Channel }\end{array}$} \\
\hline $\mathrm{CH} 2 \mathrm{CCl} 2$ & $-3.0^{e}$ & 68.84 & 16.02 & 18.71 & 20.77 & 22.36 & 24.67 & 26.27 & 28.68 & 2 & G3(MP2) \\
\hline $\mathrm{OH}$ & 9.3 & 43.88 & 7.17 & 7.09 & 7.06 & 7.06 & 7.15 & 7.33 & 7.44 & 1 & ref 21 \\
\hline C.H2CCl2OH & -23.3 & 85.93 & 23.73 & 26.86 & 29.11 & 30.78 & 33.15 & 34.84 & 37.56 & 2 & G3(MP2) \\
\hline $\mathrm{CH} 3 \mathrm{CCl} 2 \mathrm{O}$. & -18.9 & 78.92 & 21.66 & 24.91 & 27.52 & 29.62 & 32.78 & 35.01 & 38.34 & 3 & G3(MP2) \\
\hline $\mathrm{CH} 2 \mathrm{ClC} . \mathrm{ClOH}$ & -29.0 & 86.19 & 21.30 & 24.58 & 27.18 & 29.20 & 32.11 & 34.14 & 37.25 & 1 & G3(MP2) \\
\hline $\mathrm{TS} 2 f$ & -18.7 & 81.41 & 21.31 & 24.40 & 26.78 & 28.63 & 31.32 & 33.24 & 36.25 & 1 & G3(MP2) \\
\hline TS3 & -3.6 & 76.74 & 20.79 & 24.61 & 27.57 & 29.84 & 33.03 & 35.13 & 38.06 & 1 & G3(MP2) \\
\hline \multicolumn{12}{|c|}{$\begin{array}{c}\mathrm{CH}_{2} \mathrm{CCl}_{2}+\mathrm{OH} \\
\text { Beta Channel }\end{array}$} \\
\hline C. $\mathrm{Cl} 2 \mathrm{CH} 2 \mathrm{OH}$ & -23.8 & 83.91 & 21.72 & 25.10 & 27.68 & 29.65 & 32.47 & 34.43 & 37.42 & 2 & G3(MP2) \\
\hline $\mathrm{CHCl} 2 \mathrm{CH} 2 \mathrm{O}$. & -13.1 & 82.29 & 20.70 & 24.33 & 27.24 & 29.51 & 32.80 & 35.08 & 38.40 & 1 & G3(MP2) \\
\hline $\mathrm{TS} 2^{f}$ & 13.2 & 86.57 & 23.78 & 27.12 & 29.42 & 31.03 & 33.14 & 34.53 & 36.63 & 1 & G3(MP2) \\
\hline TS3 & 17.1 & 78.09 & 19.57 & 23.30 & 26.38 & 28.83 & 32.33 & 34.66 & 37.86 & 1 & G3(MP2) \\
\hline TS4 & 9.4 & 83.36 & 22.28 & 25.80 & 28.45 & 30.44 & 33.19 & 34.99 & 37.53 & 1 & G3(MP2) \\
\hline TS5 & 1.2 & 84.58 & 21.36 & 24.50 & 26.97 & 28.88 & 31.68 & 33.66 & 36.66 & 1 & G3(MP2) \\
\hline TS6 & 11.7 & 86.18 & 23.88 & 27.11 & 29.44 & 31.15 & 33.5 & 35.06 & 37.39 & 1 & CBS-Q \\
\hline \multicolumn{12}{|c|}{$\mathrm{CHClCHCl}+\mathrm{OH}$} \\
\hline $\mathrm{CHClCHCl}$ & $-2.5^{g}$ & 69.45 & 15.92 & 18.45 & 20.51 & 22.14 & 24.51 & 26.15 & 28.57 & 2 & G3(MP2) \\
\hline C. $\mathrm{HClCHClOH}$ & -26.7 & 86.82 & 21.73 & 25.04 & 27.60 & 29.55 & 32.33 & 34.28 & 37.30 & 1 & G3(MP2) \\
\hline $\mathrm{CH} 2 \mathrm{ClCHClO}$. & -16.5 & 82.85 & 20.54 & 24.21 & 27.14 & 29.42 & 32.73 & 35.01 & 38.33 & 1 & G3(MP2) \\
\hline $\mathrm{CHCl} 2 \mathrm{C} . \mathrm{HOH}$ & -23.2 & 86.45 & 21.51 & 24.76 & 27.31 & 29.27 & 32.13 & 34.13 & 37.22 & 1 & G3(MP2) \\
\hline $\mathrm{TS} 2^{f}$ & -16.9 & 82.70 & 20.81 & 23.75 & 26.17 & 28.12 & 30.96 & 32.98 & 36.12 & 1 & G3(MP2) \\
\hline TS3 & 15.6 & 87.31 & 23.21 & 26.58 & 28.94 & 30.61 & 32.84 & 34.31 & 36.51 & 1 & G3(MP2) \\
\hline TS4 & 11.8 & 78.26 & 19.52 & 23.42 & 26.55 & 29.00 & 32.47 & 34.74 & 37.88 & 1 & G3(MP2) \\
\hline TS5 & 0.5 & 84.08 & 21.67 & 25.37 & 28.12 & 30.17 & 33.20 & 34.86 & 37.46 & 1 & G3(MP2) \\
\hline TS6 & -8.7 & 84.96 & 21.35 & 24.66 & 27.16 & 29.06 & 31.80 & 33.73 & 36.67 & 1 & G3(MP2) \\
\hline TS7 & 10.6 & 86.65 & 23.68 & 26.77 & 29.10 & 30.84 & 33.28 & 34.90 & 37.31 & 1 & CBS-Q \\
\hline
\end{tabular}

${ }^{a}$ Enthalpies of formation at $0 \mathrm{~K}$, unit in kcal $/ \mathrm{mol} .{ }^{b}$ Entropy at $298 \mathrm{~K}$, unit in cal $/ \mathrm{mol} \mathrm{K}$. ${ }^{c}$ Heat capacity at $300 \leq T / \mathrm{K} \leq 1500$, unit in cal $/ \mathrm{mol}$ $\mathrm{K} .{ }^{d}$ Symmetry number included in the entropy calculation. ${ }^{e}$ Estimated based on literature value of $\Delta H_{\mathrm{f}}{ }^{\circ} 298^{22}$ and temperature correction $298-0 \mathrm{~K}$ calculated using HF/6-31G(d) determined frequencies scaled by 0.8929. ${ }^{f}$ TS numbers correspond to potential energy diagrams in Figures 6 and 7. TS1 is not shown; the rate was calculated based on VTST (see text). ${ }^{g}$ Estimated based on literature value of $\Delta H_{\mathrm{f}}{ }^{\circ} 298,{ }^{20}$ and temperature correction 298-0 K calculated using HF/6-31G(d) determined frequencies scaled by 0.8929 .

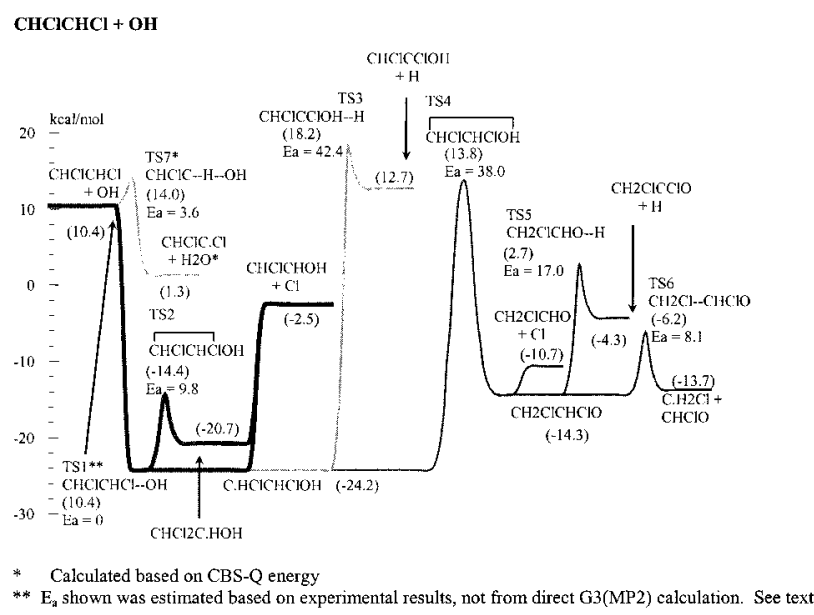

Figure 7. Potential energy diagrams for the $\mathrm{OH}$ addition to trans$\mathrm{CHClCHCl}$. Energies are $\Delta H_{\mathrm{f}}{ }^{\circ} 298$ in $\mathrm{kcal} \mathrm{mol}^{-1}$.

results and the $\mathrm{H}$ atom abstraction channel is based on the CBS-Q calculation results.

Tables 7 and 8 present the high-pressure-limit Arrhenius parameters for the various $\mathrm{OH}$ addition reaction pathways for 1,1-dichloroethylene and trans-1,2-dichloroethylene, respectively. For trans-1,2-dichloroethylene, our energy calculations along the reaction coordinate yielded a large $+2.5 \mathrm{kcal} \mathrm{mol}^{-1}$ classical barrier to reaction (see Figure 4b). This is incompatible with the observed rate constants and, for example, implies a room temperature rate constant nearly 3 orders of magnitude lower than that measured. We do not have a simple explanation for the overestimated barrier. Spin-projected PMP4/6-311+G- $(\mathrm{d}, \mathrm{p})$ theory works well for the other chlorinated ethylenes as seen in this work and elsewhere. ${ }^{10-12}$ Potential sources of error include deficiencies in the correlation treatment and basis set size, but implementation of sufficiently high levels of theory is nontrivial. Preliminary studies at the QCISD(T)-based G3(MP2) level yielded an even higher barrier of about $3 \mathrm{kcal} \mathrm{mol}^{-1}$, so presumably, much more demanding correlation treatments and/ or basis sets are needed. Another source of error might be incorrect geometries along the reaction coordinate. However, for the simplest analogue, $\mathrm{OH}+\mathrm{C}_{2} \mathrm{H}_{4}$, we have found that the $\mathrm{HF} / 6-31 \mathrm{G}(\mathrm{d}, \mathrm{p})$ values, as used here, closely match QCISD/6$311 \mathrm{G}(\mathrm{d}, \mathrm{p})$ values (and do so much better than MP2-based geometries). Without a clear resolution of the origin of the qualitatively incorrect VTST rate constants for $\mathrm{OH}+$ trans$\mathrm{CHCl}=\mathrm{CHCl}$, subsequent kinetic modeling of this reaction was instead based on a temperature-independent rate constant of $2.0 \times 10^{-12} \mathrm{~cm}^{3}$ molecule ${ }^{-1} \mathrm{~s}^{-1}$. This value is a composite of all prior measurements of $k_{2}$ at low temperatures. Ab initio VTST data were employed for the entrance channels for the other pathways.

Figures 8 and 9 present a comparison of the experimental data with QRRK predictions in Arrhenius form at $p=1 \mathrm{~atm}$ for $\mathrm{OH}$ addition to 1,1-dichloroethylene and 1,2-dichloroethylene, respectively. For 1,1-dichloroethylene, the agreement between the overall forward rate for the $\beta$ channel (represented exclusively by the stabilization rate) and the experimental data is excellent between 293 and $640 \mathrm{~K}$. The reverse reaction begins to dominate above $650 \mathrm{~K}$ and is responsible for the rapid dropoff in the observed bimolecular rate coefficients between 640 and $\sim 700 \mathrm{~K}$. The well depth for the $\beta$-channel was reduced by 
TABLE 6: Calculated Energy of Reactant, Intermediate Radicals, and Products at $0 \mathrm{~K}^{a}$

\begin{tabular}{|c|c|c|}
\hline & G3(MP2) & CBS-Q \\
\hline \multicolumn{3}{|c|}{$\mathrm{CH} 2 \mathrm{CCl} 2+\mathrm{OH}$} \\
\hline \multicolumn{3}{|c|}{ Alpha Channel } \\
\hline $\mathrm{CH} 2 \mathrm{CCl} 2$ & -996.75312 & -996.73466 \\
\hline $\mathrm{OH}$ & -75.65469 & -75.64887 \\
\hline C.H2CCl2OH & -1072.45502 & \\
\hline CH3CCl2O. & -1072.44796 & \\
\hline $\mathrm{CH} 2 \mathrm{ClC} . \mathrm{ClOH}$ & -1072.46400 & \\
\hline $\mathrm{CH} 2 \mathrm{CClOH}$ & -612.74403 & \\
\hline $\mathrm{CH} 3 \mathrm{CClO}$ & -612.77840 & \\
\hline $\mathrm{H}$ & -0.50184 & \\
\hline $\mathrm{Cl}$ & -459.68724 & \\
\hline TS1 & -1072.40189 & \\
\hline TS2 & -1072.44758 & \\
\hline TS3 & -1072.42362 & \\
\hline \multirow{2}{*}{\multicolumn{3}{|c|}{$\begin{array}{c}\mathrm{CH}_{2} \mathrm{CCl}_{2}+\mathrm{OH} \\
\text { Beta Channel }\end{array}$}} \\
\hline & & \\
\hline C.Cl2CH2OH & -1072.45579 & \\
\hline $\mathrm{CHCl} 2 \mathrm{CH} 2 \mathrm{O}$. & -1072.4387 & \\
\hline $\mathrm{CCl} 2 \mathrm{CHOH}$ & -1071.89554 & \\
\hline $\mathrm{CHCl} 2 \mathrm{CHO}$ & -1071.9091 & \\
\hline $\mathrm{CH} 2 \mathrm{O}$ & -114.35303 & \\
\hline C.HCl2 & -958.0752438 & \\
\hline $\mathrm{CCl} 2 \mathrm{C} . \mathrm{H}$ & -996.07095 & -996.05536 \\
\hline $\mathrm{H} 2 \mathrm{O}$ & -76.34241 & -76.33648 \\
\hline TS1 & -1072.40777 & \\
\hline TS2 & -1072.4029 & \\
\hline TS3 & -1072.39067 & \\
\hline TS4 & -1072.4029 & \\
\hline TS5 & -1072.41594 & \\
\hline TS6 & -1072.393966 & -1072.37499 \\
\hline \multicolumn{3}{|c|}{$\mathrm{CHClCHCl}+\mathrm{OH}$} \\
\hline $\mathrm{CHClCHCl}$ & -996.75284 & -996.73471 \\
\hline C. $\mathrm{HClCHClOH}$ & -1072.46101 & \\
\hline $\mathrm{CH} 2 \mathrm{ClCHClO}$. & -1072.44474 & \\
\hline $\mathrm{CHCl} 2 \mathrm{C} . \mathrm{HOH}$ & -1072.45542 & \\
\hline $\mathrm{CHClCHOH}$ & -612.74013 & \\
\hline $\mathrm{CHClCClOH}$ & -1071.90162 & \\
\hline $\mathrm{CH} 2 \mathrm{ClCHO}$ & -612.75311 & \\
\hline $\mathrm{CH} 2 \mathrm{ClCClO}$ & -1071.92910 & \\
\hline $\mathrm{CHClO}$ & -573.53045 & \\
\hline C.H2Cl & -498.91605 & \\
\hline CHClC.Cl & -996.07837 & -996.06222 \\
\hline TS1 & -1072.40501 & \\
\hline TS2 & -1072.44537 & \\
\hline TS3 & -1072.39352 & \\
\hline TS4 & -1072.39970 & \\
\hline TS5 & -1072.41766 & \\
\hline TS6 & -1072.43222 & \\
\hline TS7 & -1072.39650 & -1072.37756 \\
\hline
\end{tabular}

${ }^{a}$ Unit in Hartree. TS numbers correspond to potential energy diagrams in Figures 6 and 7.

$2 \mathrm{kcal} \mathrm{mol}^{-1}$ to improve the fit to the data above $500 \mathrm{~K}$. This is well within the uncertainty of the ab initio calculations and is consistent with an estimate of the enthalpy of formation of the $\mathrm{CH}_{2}(\mathrm{OH}) \mathrm{CCl}_{2}$ adduct based on equilibrium considerations observed in the experimental measurements between 640 and $700 \mathrm{~K}$ (see below). For 1,2-dichloroethylene, the excellent agreement between the overall forward rate (the sum of the stabilization and chlorine elimination channels) and the experimental data is fortuitous because of the lack of any substantial temperature dependence in the measurements.

Figure 8 also shows the QRRK estimated temperaturedependent reaction rate constants for 1,1-dichloroethylene. The predicted dominant product is $\mathrm{CCl}_{2} \mathrm{CH}_{2} \mathrm{OH}$, the stabilized product formed by $\mathrm{OH}$ addition to the $\beta$ site. $\mathrm{OH}$ addition to the $\alpha$ site becomes important above $1000 \mathrm{~K}$. Above $1000 \mathrm{~K}$, $\mathrm{OH}$ addition to the $\alpha$ site followed by $\mathrm{Cl}$ elimination leads to

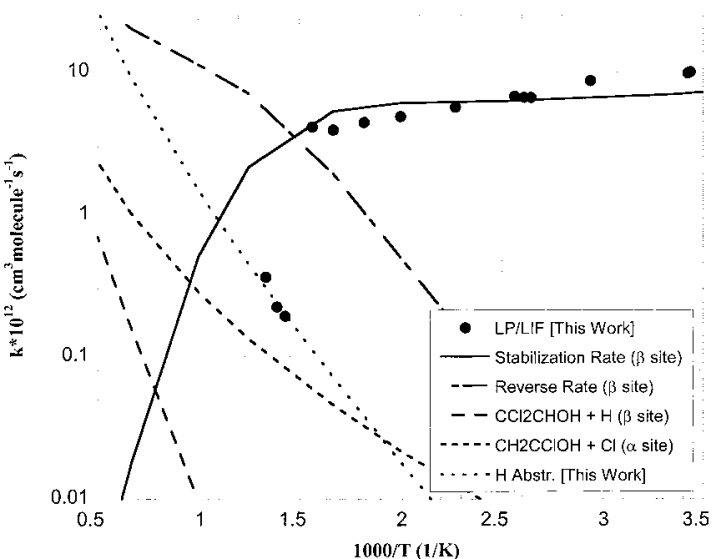

Figure 8. Comparison of experimental results with the QRRK model results for $k_{1}(p=1 \mathrm{~atm})$. Shown are the stabilization rate, reverse rate and $\mathrm{H}$ elimination channel for the $\beta$ site, and the chlorine elimination channel for the $\alpha$ site. Also shown is the ab initio based TST calculation of the $\mathrm{H}$-atom abstraction channel.

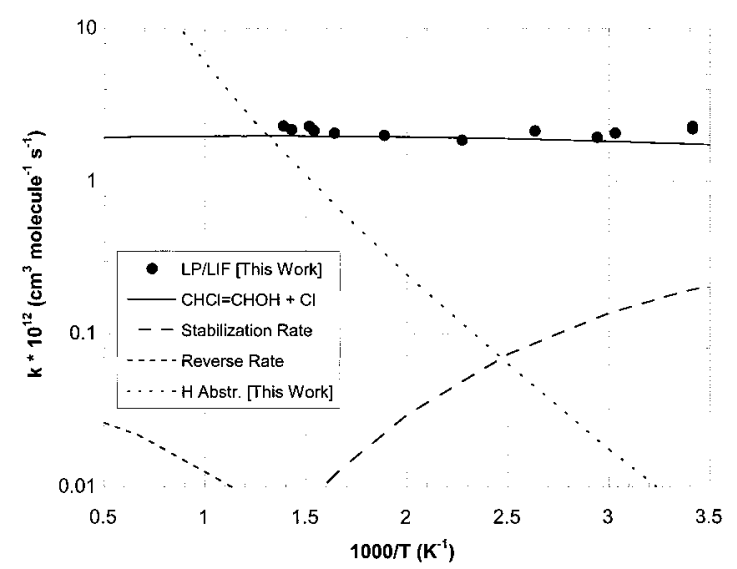

Figure 9. Comparison of experimental results with the QRRK model results for $k_{2}(p=1 \mathrm{~atm})$. Shown are the chlorine elimination rate, stabilization rate, reverse reaction, hydrogen elimination channel, and the ab initio based TST calculation of the $\mathrm{H}$-atom abstraction channel.

the formation of $\mathrm{CH}_{2}=\mathrm{CClOH}$. At temperatures approaching $2000 \mathrm{~K}, \mathrm{OH}$ addition to the $\beta$ site followed by $\mathrm{H}$ elimination produces $\mathrm{CCl}_{2}=\mathrm{CHOH}$. The rate of formation of these chemically activated reaction products is small compared to the predicted rate of $\mathrm{H}$-atom abstraction (see below). It should be noted that $\alpha$ and $\beta$ addition pathways can only be considered separately if $\mathrm{OH}$ migration between the carbon atoms does not occur.

Figure 9 also illustrates the QRRK estimated temperaturedependent reaction rate constants for 1,2-dichloroethylene. The dominant product is $\mathrm{CHCl}=\mathrm{CHOH}$, formed by $\mathrm{OH}$ addition followed by $\mathrm{Cl}$ atom elimination. The stabilization reaction accounts for $<10 \%$ of the overall rate at room temperature and becomes less significant at higher temperatures. The reverse of $\mathrm{OH}$ addition is insignificant under all reaction conditions.

Figures 8 and 9 also present TST calculations for the respective $\mathrm{H}$-atom abstraction channels for 1,1-dichloroethylene and 1,2-dichloroethylene, respectively. For 1,1-dichloroethylene, a CBS-Q composite ab initio calculation yielded an activation energy of $5.16 \mathrm{kcalmol}^{-1}$. A $<1 \mathrm{kcal} \mathrm{mol}^{-1}$ barrier increase and the entropy of activation calculated from the ab initio-based geometry of the transition state yield a rate (see Table 5) that is in good agreement with the experimental measurements between 700 and $750 \mathrm{~K}$. This contrasts with the QRRK-based $\mathrm{Cl}$ elimination channel ( $\mathrm{OH}$ attack at the $\alpha$ site) that is a factor 
TABLE 7: QRRK Input Parameters Rate Constants for $\mathrm{OH}$ Addition to $\mathrm{CH}_{2}=\mathrm{CCl}_{2}$

\begin{tabular}{|c|c|c|c|}
\hline \multicolumn{4}{|c|}{ A. $\alpha$ site $^{a}$} \\
\hline reaction & $\begin{array}{c}B \\
\left(\mathrm{~s}^{-1} \text { or } \mathrm{cm}^{3} /(\text { molecule })\right)\end{array}$ & $n$ & $\begin{array}{c}C \\
\left(\mathrm{kcal} \mathrm{mol}^{-1}\right)\end{array}$ \\
\hline 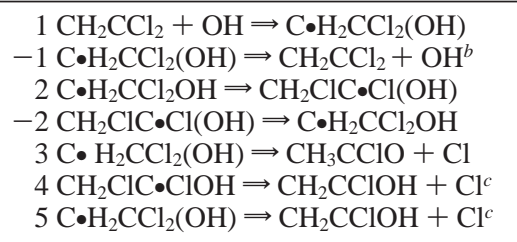 & $\begin{array}{l}3.26 \times 10^{-20} \\
1.19 \times 10^{10} \\
3.04 \times 10^{11} \\
9.73 \times 10^{9} \\
6.39 \times 10^{8} \\
3.90 \times 10^{13} \\
3.90 \times 10^{13}\end{array}$ & $\begin{array}{l}2.44 \\
0.82 \\
0.23 \\
0.82 \\
0.77 \\
0.00 \\
0.00\end{array}$ & $\begin{array}{r}1.73 \\
32.60 \\
4.80 \\
10.40 \\
19.06 \\
18.70 \\
24.50\end{array}$ \\
\hline \multicolumn{4}{|c|}{ B. $\beta$ site $^{d}$} \\
\hline reaction & $\begin{array}{c}B \\
\left(\mathrm{~s}^{-1} \text { or } \mathrm{cm}^{3} /(\text { molecule } / \mathrm{s})\right)\end{array}$ & $n$ & $\begin{array}{c}C \\
\left(\mathrm{kcal} \mathrm{mol}^{-1}\right)\end{array}$ \\
\hline 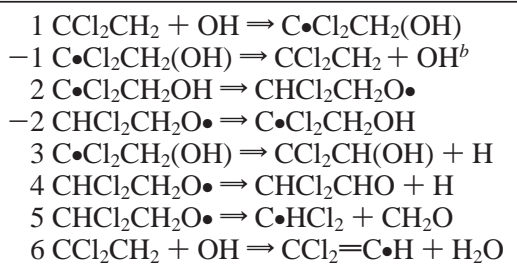 & $\begin{array}{l}5.28 \times 10^{-18} \\
3.02 \times 10^{7} \\
2.96 \times 10^{8} \\
1.78 \times 10^{10} \\
5.83 \times 10^{11} \\
9.81 \times 10^{9} \\
2.29 \times 10^{12} \\
3.06 \times 10^{-17}\end{array}$ & $\begin{array}{l}2.00 \\
2.11 \\
0.81 \\
0.70 \\
0.65 \\
1.41 \\
0.51 \\
2.00\end{array}$ & $\begin{array}{r}-1.60 \\
26.48 \\
40.80 \\
30.13 \\
38.02 \\
22.70 \\
15.08 \\
6.00\end{array}$ \\
\hline
\end{tabular}

${ }^{a}$ Grouped geometric mean frequencies of the adduct with effective degeneracies: $361.2 \mathrm{~cm}^{-1}(9.376), 1137.1 \mathrm{~cm}^{-1}(4.688), 3270.5 \mathrm{~cm}^{-1}(2.936)$. Lennard-Jones parameters: $\mathrm{CH}_{2} \mathrm{CCl}_{2} \mathrm{OH}$ adduct, $\sigma=5.198 \AA, \in / k=533.08 \mathrm{~K}$; He bath gas, $\sigma=2.576 \AA$, $\in / k=470.00 \mathrm{~K}$. ${ }^{b}$ Rate was estimated based on forward rate constant and principle of microscopic reversibility. ${ }^{c}$ Arrhenius $\mathrm{A}$ factor for $\mathrm{Cl}$ elimination reaction was adopted from the reaction: $\mathrm{C}_{2} \mathrm{H}_{4} \mathrm{Cl} \rightarrow \mathrm{C}_{2} \mathrm{H}_{4}+\mathrm{Cl}$, ref 33. ${ }^{d}$ Grouped geometric mean frequencies of the adduct with effective degeneracies: $150.0 \mathrm{~cm}^{-1}(4.327)$, $710.1 \mathrm{~cm}^{-1}$ (8.386), $2178.9 \mathrm{~cm}^{-1}$ (4.287). Lennard-Jones parameters: $\mathrm{CCl}_{2} \mathrm{CH}_{2} \mathrm{OH}$ (adduct), $\sigma=5.198 \AA$, $\in / k=533.08 \mathrm{~K}$; He (bath gas), $\sigma=$ $2.576 \AA, \in / k=470.00 \mathrm{~K}$.

of 4 lower than experimental measurements above $700 \mathrm{~K}$. Experiments where $\mathrm{Cl}$ atoms were intentionally generated from the $193 \mathrm{~nm}$ photolysis of 1,1-dichloroethylene suggest that the $\mathrm{Cl}$ atom elimination channel is not attributable to the experimental data above $700 \mathrm{~K}$. The $\mathrm{Cl}$ atoms result in a series of secondary reactions that resulted in an effective bimolecular rate constant on the order of $6 \pm 1 \times 10^{-13} \mathrm{~cm}^{3}$ molecule ${ }^{-1} \mathrm{~s}^{-1}$. This rate was observed to be temperature-independent between 700 and $900 \mathrm{~K}$. Kinetic isotope measurements for 1,1-dichloroethylene at $720 \mathrm{~K}$ were inconclusive and were not repeated because of the high cost of the deuterated standard. For 1,2dichloroethylene, a similar CBS-Q composite ab initio calculation yielded an activation energy for this reaction of $3.6 \mathrm{kcal}$ $\mathrm{mol}^{-1}$. This barrier and the entropy of activation calculated from the ab initio-based geometry of the transition state yield a rate (see Table 6) that is a factor of 40 lower than experimental measurements at $400 \mathrm{~K}$ and a factor of 2 lower than experimental measurements at $720 \mathrm{~K}$. These calculations (and the experimental measurements for 1,2-dichloroethylene) indicate that the $\mathrm{H}$-atom abstraction channel is not important below temperatures of $\sim 800 \mathrm{~K}$. At higher temperatures, $\mathrm{H}$ abstraction is the dominant $\mathrm{OH}$ reaction mechanism for both of these chloroethylenes.

The predicted reaction mechanism for 1,1-dichloroethylene is consistent with the low temperature product analysis previously reported by Kirchner et al. ${ }^{8}$ The dominant reaction product was the stabilized adduct from $\mathrm{OH}$ attack at the $\beta$ site. There was little evidence for $\mathrm{Cl}$ atom elimination reactions. The only previous product study for 1,2-dichloroethylene involved the smog chamber study of Tuazon et al. ${ }^{6}$ FTIR measurements indicated that $\mathrm{Cl}$ elimination reactions were occurring. However, the experimental conditions of the smog chamber experiments are more complex than those modeled in this study, and a direct comparison of observed reaction products with the QRRKpredicted results presented here is not valid.

Figure 10 illustrates the effect of pressure on the QRRK estimated adduct stabilization reaction (and the reverse) for 1,1-

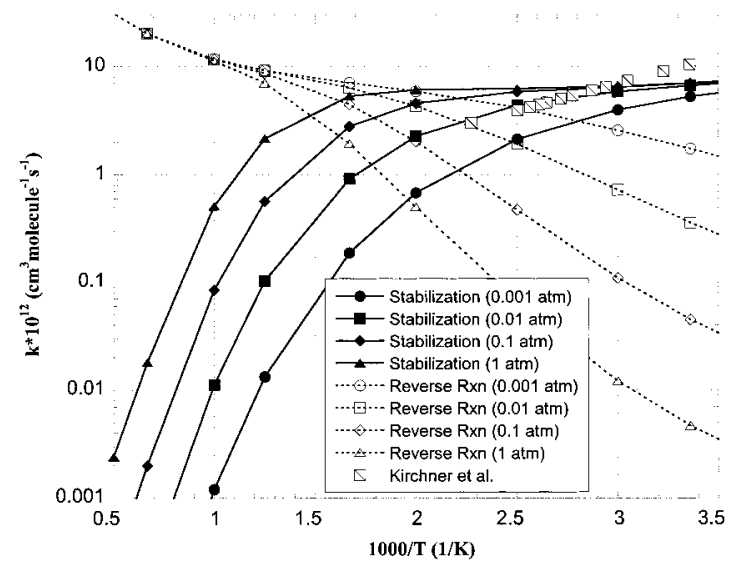

Figure 10. Arrhenius plot of the QRRK model results for $k_{1}$ at 0.001 , $0.01,0.1$, and $1 \mathrm{~atm}$. Shown are the adduct stabilization channel and the reverse reaction for the $\beta$ site.

dichloroethylene. The modeling results indicate that all prior measurements (including this study) were obtained in the falloff region at temperatures at and above room temperature. Prior measurements of this reaction (typically at room temperature) at pressures ranging from $\sim 1-5$ Torr $^{1}$ to $\sim 25-50$ Torr $^{8}$ did not exhibit pressure effects. This was likely due to a lack of sufficient accuracy to resolve the QRRK predicted 10 to $20 \%$ change in rate constant with increasing pressure at these low temperatures. As shown in Figure 10, the larger negative temperature dependence observed in the measurements of Kirchner et al. ${ }^{1}$ can be explained because of pressure effects.

The crossover between stabilization and reverse (redissociation) channels shown in Figure 10 indicates that equilibration for the addition channel

$$
\mathrm{CH}_{2}=\mathrm{CCl}_{2}+\mathrm{OH} \leftrightarrow \mathrm{CH}_{2}(\mathrm{OH})-\mathrm{CCl}_{2}\left(k_{1 \mathrm{a}}, k_{-1 \mathrm{a}}\right)
$$

becomes important in the 600-700 K regime, consistent with the sharp drop observed in the total rate constant $k_{1}$. The decays 
TABLE 8: QRRK Input Parameters Rate Constants for $\mathrm{OH}$ Addition to trans-CHCl=CHCl${ }^{a}$

\begin{tabular}{|c|c|c|c|}
\hline reactions & $\begin{array}{c}B \\
\left(\mathrm{~s}^{-1} \text { or } \mathrm{cm}^{3} /(\text { molecule } \mathrm{s})\right)\end{array}$ & $n$ & $\begin{array}{c}C \\
\left(\mathrm{kcal} \mathrm{mol}^{-1}\right)\end{array}$ \\
\hline $1 \mathrm{CHClCHCl}+\mathrm{OH} \rightarrow \mathrm{C} \cdot \mathrm{HClCHCl}(\mathrm{OH})$ & $2.00 \times 10^{-12}$ & 0.00 & 0.00 \\
\hline$-1 \mathrm{C} \cdot \mathrm{HClCHCl}(\mathrm{OH}) \rightarrow \mathrm{CHClCHCl}+\mathrm{OH}^{b}$ & $1.44 \times 10^{20}$ & -2.13 & 35.76 \\
\hline $2 \mathrm{C} . \mathrm{HClCHCl}(\mathrm{OH}) \rightarrow \mathrm{CCl}_{2} \mathrm{HC} \cdot \mathrm{H}(\mathrm{OH})$ & $2.43 \times 10^{11}$ & 0.33 & 10.21 \\
\hline$-2 \mathrm{CCl}_{2} \mathrm{HC} \cdot \mathrm{H}(\mathrm{OH}) \rightarrow \mathrm{C} \cdot \mathrm{HClCHCl}(\mathrm{OH})$ & $1.65 \times 10^{11}$ & 0.41 & 6.67 \\
\hline $3 \mathrm{C} . \mathrm{HClCHCl}(\mathrm{OH}) \rightarrow \mathrm{CH}_{2} \mathrm{ClCHClO}^{\circ}$ & $3.33 \times 10^{12}$ & 0.92 & 38.32 \\
\hline$-3 \mathrm{CH}_{2} \mathrm{ClCHClO} \bullet \rightarrow \mathrm{C} . \mathrm{HClCHCl}(\mathrm{OH})$ & $7.58 \times 10^{9}$ & 0.79 & 28.37 \\
\hline $4 \mathrm{C} . \mathrm{HClCHCl}(\mathrm{OH}) \rightarrow \mathrm{CHCl}=\mathrm{CHOH}+\mathrm{Cl}$ & $3.90 \times 10^{13}$ & 0.00 & 21.70 \\
\hline $5 \mathrm{C} \cdot \mathrm{HClCHCl}(\mathrm{OH}) \rightarrow \mathrm{CHCl}=\mathrm{CClOH}+\mathrm{H}$ & $6.87 \times 10^{9}$ & 1.24 & 42.43 \\
\hline $6 \mathrm{CHCl}_{2} \mathrm{C} \cdot \mathrm{HOH} \rightarrow \mathrm{CHCl}=\mathrm{CHOH}+\mathrm{Cl}^{c}$ & $3.90 \times 10^{13}$ & 0.00 & 18.18 \\
\hline $7 \mathrm{CHClCHCl}+\mathrm{OH} \rightarrow \mathrm{C} . \mathrm{ClCHCl}+\mathrm{H}_{2} \mathrm{O}$ & $3.10 \times 10^{-17}$ & 2.00 & 3.60 \\
\hline
\end{tabular}

${ }^{a}$ Grouped geometric mean frequencies of the adduct with effective degeneracies: $338.7 \mathrm{~cm}^{-1}(7.46), 1110.1 \mathrm{~cm}^{-1}(6.52), 3222.0 \mathrm{~cm}^{-1}(3.02)$. Lennard-Jones parameters: $\mathrm{CHClCHClOH}$ (adduct), $\sigma=5.327 \AA, \in / k=469.42 \mathrm{~K}$; He (bath gas), $\sigma=2.576 \AA$, $\in / k=470.00 \mathrm{~K} .{ }^{b} \mathrm{Rate}$ was estimated based on forward rate constant and principle of microscopic reversibility. ${ }^{c}$ Arrhenius $\mathrm{A}$ factor for $\mathrm{Cl}$ elimination reaction was adopted from the reaction: $\mathrm{C}_{2} \mathrm{H}_{4} \mathrm{Cl} \rightarrow \mathrm{C}_{2} \mathrm{H}_{4}+\mathrm{Cl}$, ref 33 .

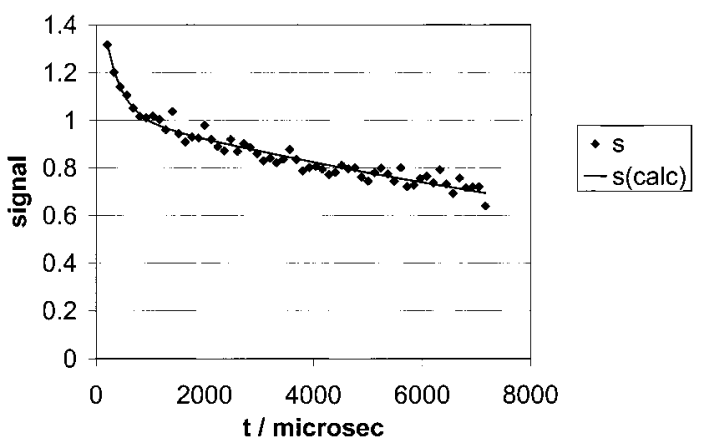

Figure 11. Biexponential $\mathrm{OH}$ decay and resulting fit to the data using reactions $k_{1 \mathrm{a}}, k_{-1 \mathrm{a}}$, and $k_{\mathrm{d}}$ and eq 3 (see text). $T=680 \mathrm{~K},\left[\mathrm{CH}_{2^{-}}\right.$ $\left.\mathrm{CCl}_{2}\right]_{0}=3.35 \times 10^{14}$ molecules $\mathrm{cm}^{-3}$.

at $680 \mathrm{~K}$, in the middle of the drop-off region, show modest deviations from simple exponential behavior. If they are forced to fit pseudo-first-order kinetics, the resulting $k_{1}$ value lies between the values at 640 and $700 \mathrm{~K}$ (see Table 3). For a more detailed analysis of the equilibration region, we considered the following mechanism:

$$
\begin{aligned}
\mathrm{OH}+\mathrm{CH}_{2} \mathrm{CCl}_{2} \rightarrow \text { adduct } & k_{1 \mathrm{a}} \\
\text { adduct } \rightarrow \mathrm{OH}+\mathrm{CH}_{2} \mathrm{CCl}_{2} & k_{-1 \mathrm{a}} \\
\mathrm{OH} \rightarrow \text { loss } & k_{\mathrm{d}}
\end{aligned}
$$

This is a simplified form of a similar mechanism analyzed by Wine and co-workers, ${ }^{30}$ and the corresponding expression for the fluorescence signal $S_{t}$ is

$$
\begin{aligned}
& S_{t}=\text { background }+ \\
& \qquad S_{0} \frac{\left(k_{-1 \mathrm{a}}+\lambda_{1}\right) \exp \left(\lambda_{1} t\right)-\left(k_{-1 \mathrm{a}}+\lambda_{2}\right) \exp \left(\lambda_{2} t\right)}{\lambda_{1}-\lambda_{2}}
\end{aligned}
$$

where $S_{t}$ is the total signal at time $t$, the background is a constant arising from scattered light, $S_{0}$ is the LIF intensity at $t=0$, and $\lambda_{1}$ and $\lambda_{2}$ are given by

$$
\lambda_{1,2}=\frac{-a \pm \sqrt{a^{2}-4 k_{\mathrm{d}} k_{-1 \mathrm{a}}}}{2}
$$

where $a=k_{-1 \mathrm{a}}+k_{\mathrm{d}}+k_{1 \mathrm{a}}\left[\mathrm{CH}_{2} \mathrm{CCl}_{2}\right]$.

The decays at $680 \mathrm{~K}$ were analyzed as follows with a resulting fit shown in Figure 11. First, $k_{\mathrm{d}}$ was fixed from a run with $\left[\mathrm{CH}_{2}-\right.$ $\left.\mathrm{CCl}_{2}\right]=0$ by a fit of $S_{t}$ to a simple exponential decay plus background. The remaining decays were fit directly to eq 3 with the background, $S_{0}$, and $k_{-1 \mathrm{a}}$ as the only adjustable parameters. $k_{1}$ was set to $3.84 \times 10^{-12} \mathrm{~cm}^{3}$ molecule ${ }^{-1} \mathrm{~s}^{-1}$ from a small extrapolation of the Arrhenius expression derived for 291-640 $\mathrm{K} . k_{-1 \mathrm{a}}$ is not determined very precisely: the derived $k_{-1 \mathrm{a}}$ values range from 1000 to $2100 \mathrm{~s}^{-1}$ and their mean is $1550 \pm 510 \mathrm{~s}^{-1}$ $( \pm 2 \sigma$ of the mean), but these data do permit precise determination of the adduct binding energy. The concentration equilibrium constant for the adduct formation channel $1 \mathrm{a}, K_{\mathrm{c}}=k_{1 \mathrm{a}} \mathrm{l}$ $k_{-1 \mathrm{a}}$, is $2.5 \times 10^{-15} \mathrm{~cm}^{3}$ molecule ${ }^{-1}$ at $680 \mathrm{~K}$. Relative to a standard state of $10^{5} \mathrm{~Pa}, K_{\mathrm{eq}}=2.6 \times 10^{4}$. Use of $\Delta S=-28.2$ cal $\mathrm{K}^{-1} \mathrm{~mol}^{-1}$ derived from the data in Table 7, together with $\Delta G=-R T \ln K_{\mathrm{eq}}=\Delta H-T \Delta S$, implies $\Delta H=-32.9 \mathrm{kcal}$ $\mathrm{mol}^{-1}$. We allow for a factor of 3 uncertainty in $K_{\mathrm{eq}}$ to obtain error limits of $\pm 1.5 \mathrm{kcal} \mathrm{mol}^{-1}$.

Correction of this $\Delta H$ to $298 \mathrm{~K}$ and using the $C_{\mathrm{p}}$ data (Table 7) yields a $\mathrm{C}-\mathrm{O}$ bond dissociation enthalpy (BDE) of $32.8 \pm$ $1.5 \mathrm{kcal} \mathrm{mol}^{-1}$. This corresponds to a $0 \mathrm{~K}$ value of $31.9 \pm 1.5$ $\mathrm{kcal} \mathrm{mol}^{-1}$. An independent test of the BDE for $\mathrm{OH}+1,1-$ dichloroethylene effect comes from the data of Table 3, which imply $\mathrm{BDE}_{298}=31.3 \mathrm{kcal} \mathrm{mol}^{-1}$. These values are somewhat larger than the BDE determined by Fulle et al. ${ }^{31}$ for the analogous $\mathrm{OH}+$ ethylene adduct, of $29.4 \pm 1.4 \mathrm{kcal} \mathrm{mol}^{-1}$ at $0 \mathrm{~K}$. Apparently, chlorine substitution stabilizes to a small degree the radical center in the adduct.

\section{Summary}

New atmospheric pressure, absolute rate measurements are presented for the reaction of $\mathrm{OH}$ radicals with 1,1-dichloroethylene $\left(k_{1}\right)$ and trans-1,2-dichloroethylene $\left(k_{2}\right)$. The new kinetic measurements (and modeling results) are consistent with prior lower temperature measurements for both substrates. The data for $k_{1}$ (below $640 \mathrm{~K}$ ) and $k_{2}$ were successfully modeled by conducting an ab initio based reaction pathway analysis based on an $\mathrm{OH}$ addition mechanism. Variational TST calculations of the entrance channel were consistent with the experimental measurements for $k_{1}$ but incorrectly predict a significant barrier for addition of $\mathrm{OH}$ to trans-1,2-dichloroethylene. The reason for the discrepancy for the second reaction is unclear. Adduct stabilization was found to be the dominant mechanism for 1,1dichloroethylene below $700 \mathrm{~K}$, hence, the observed negative temperature-dependence. Analysis of equilibration in this system yields a $\mathrm{C}-\mathrm{O}$ bond dissociation enthalpy of $32.8 \pm 1.5 \mathrm{kcal}$ $\mathrm{mol}^{-1}$ at $298 \mathrm{~K}$, a value confirmed by ab initio calculations. $\mathrm{Cl}$ elimination was found to be the dominant mechanism for trans1,2-dichloroethylene at all temperatures. Ab initio based TST calculations for the respective $\mathrm{H}$-atom abstraction channels indicated that this mechanism is important at temperatures above 700 and $800 \mathrm{~K}$ for $k_{1}$ and $k_{2}$, respectively. At flame temperatures, 
$\mathrm{H}$ atom abstraction will be the dominant mechanism of $\mathrm{OH}$ attack for both substrates.

Just prior to submitting this manuscript for publication, we became aware of a recently published room temperature study of the $\mathrm{OH}$-initiated oxidation of the chlorinated ethylenes. ${ }^{32}$ This experimental study, using the discharge-flow technique, also reported measurements of $\mathrm{Cl}$ atom production following the $\mathrm{OH}-$ initiated reaction. For 1,2-dichloroethylene, the room temperature chlorine atom yield was essentially unity, whereas for 1,1dichloroethylene, the chlorine atom yield was essentially zero. The $\mathrm{Cl}$ atom yields and the room-temperature rate constants for $\mathrm{OH}$ reaction with 1,1- and 1,2-dichloroethylene are consistent with the experimental data and mechanistic analysis presented herein.

Acknowledgment. The authors acknowledge support from the Environmental Protection Agency (Grant R82-6169-01-0). Although this research has been supported by the US-EPA, it has not been subject to Agency review and therefore does not necessarily reflect the views of the Agency, and no official endorsement should be inferred. P.M. also thanks the R.A. Welch Foundation (Grant B-1174) and UNT for support. Some of the calculations were performed on the National Computational Science Alliance SGI/Cray Origin 2000 (Grant CHE000015N) and at facilities generously provided by the Materials and Manufacturing Division of the Air Force Research Laboratory at Wright-Patterson AFB, Ohio.

Supporting Information Available: Table $1 \mathrm{~S}$ and $2 \mathrm{~S}$ present computed molecular geometries and vibrational frequencies for reactants, intermediate radicals, transition states, and products except $\mathrm{OH}$ and $\mathrm{H}_{2} \mathrm{O}$. This material is available free of charge via the Internet at http://pubs.acs.org.

\section{References and Notes}

(1) Kirchner, K.; Helf, D.; Ott, P.; Vogt, S. Ber. Bunsen-Ges. Phys. Chem. 1990, 94, 77.

(2) Ramamoorthy, S.; Ramamoorthy, S. Chlorinated Organic Compounds in the Environment; Lewis Publishers: New York, 1997; Chapter 3.

(3) Fairchild, P. W.; Smith, G. P.; Crosley, D. R. Proc. Combust. Inst. 1982, 19, 107.

(4) Warnatz, J.; Bockhorn, H.; Moser, A.; Wenz, H. W. Proc. Combust. Inst. 1982, 19, 197.

(5) Edney, E. O.; Kleindienst, T. E.; Corse, E. W. Int. J. Chem. Kinet. 1986, $18,1355$.

(6) Tuazon, E. C.; Atkinson, R. A.; Aschmann, S. M.; Goodman, M. A.; Winer, A. M. Int. J. Chem. Kinet. 1988, 20, 241.

(7) Zhang, Z.; Liu, R.; Huie, R. E.; Kurylo, M. J. J. Phys. Chem. 1991, 95, 194.

(8) Abbatt, J. P. D.; Anderson, J. G. J. Phys. Chem. 1991, 95, 2382.

(9) Atkinson, R. J. Phys. Chem. Ref. Data 1989, Monograph 1.

(10) Tichenor, L. B.; Taylor, P. H.; Yamada, T.; Peng, J.; Hu, X.; Marshall, P. J. Phys. Chem. A. 2000, 104, 1700.
(11) Tichenor, L. B.; El-Sinawi, A.; Taylor, P. H.; Yamada, T.; Peng, J.; Hu, X.; Marshall, P. Chemosphere 2001, 42, 571.

(12) Tichenor, L. B.; Lozada-Ruiz, A. J.; Yamada, T.; El-Sinawi, A.; Taylor, P. H.; Peng, J.; Hu, X.; Marshall, P. Proc. Combust. Inst. 2000, 28, 1495.

(13) Febo, A.; Perrino, C.; Gherardi, M.; Sparapani, R. Environ. Sci. Technol. 1995, 29, 2390.

(14) Brust, A. S.; Becker, K. H.; Kleffmann, J.; Wiesen, P. Atmos. Environ. 2000, 34, 13.

(15) Wollenhaupt, M.; Carl, S. A.; Horowitz, A.; Crowley, J. N. J. Phys. Chem. 2000, 104, 2695.

(16) Cox, R. A. J. Photochem. 1974, 3, 175.

(17) Curtiss, L. A.; Redfern, P. C. J. Chem. Phys. 1999, 110, 47034709.

(18) Frisch, M. J.; Trucks, G. W.; Schlegel, H. B.; Gill, P. M. W.; Johnson, B. G.; Robb, M. A.; Cheeseman, J. R.; Keith, T.; Petersson, G. A.; Montgomery, J. A.; Raghavachari, K.; Al-Laham, M. A.; Zakrzewski, V. G.; Ortiz, J. V.; Foresman, J. B.; Cioslowski, J.; Stefanov, B. B.; Nanayakkara, A.; Challacombe, M.; Peng, C. Y.; Ayala, P. Y.; Chen, W.; Wong, M. W.; Andres, J. L.; Replogle, E. S.; Gomperts, R.; Martin, R. L.; Fox, D. J.; Binkley, J. S.; Defrees, D. J.; Baker, J.; Stewart, J. P.; HeadGordon, M.; Gonzalez, C.; Pople, J. A. Gaussian 94; Gaussian, Inc.: Pittsburgh, PA, 1995

(19) Frisch, M. J.; Trucks, G. W.; Schlegel, H. B.; Scuseria, G. E.; Robb, M. A.; Cheeseman, J. R.; Zakrzewski, V. G.; Montgomery, J. A., Jr.; Stratmann, R. E.; Burant, J. C.; Dapprich, S.; Millam, J. M.; Daniels, A D.; Kudin, K. N.; Strain, M. C.; Farkas, O.; Tomasi, J.; Barone, V.; Cossi, M.; Cammi, R.; Mennucci, B.; Pomelli, C.; Adamo, C.; Clifford, S.; Ochterski, J.; Petersson, G. A.; Ayala, P. Y.; Cui, Q.; Morokuma, K.; Malick, D. K.; Rabuck, A. D.; Raghavachari, K.; Foresman, J. B.; Cioslowski, J.; Ortiz, J. V.; Stefanov, B. B.; Liu, G.; Liashenko, A.; Piskorz, P.; Komaromi, I.; Gomperts, R.; Martin, R. L.; Fox, D. J.; Keith, T.; Al-Laham, M. A.; Peng, C. Y.; Nanayakkara, A.; Gonzalez, C.; Challacombe, M.; Gill, P. M. W.; Johnson, B. G.; Chen, W.; Wong, M. W.; Andres, J. L.; Head-Gordon, M.; Replogle, E. S.; Pople, J. A. Gaussian 98, revision x.x; Gaussian, Inc.: Pittsburgh, PA, 1998.

(20) Stull, D. R.; Westrum, E. F., Jr.; Sinke, G. C. The Chemical Thermodynamics of Organic Compounds; John Wiley \& Sons: New York, 1969.

(21) Stull, D. R.; Prophet, H. JANAF Thermochemical Tables, NSRDSNBS 37; U. S. Government Printing Office: Washington, DC, 1971.

(22) Mansson, R.; Ringer, B.; Sunner, S. J. Chem. Thermodyn. 1971, 3,547 .

(23) Hehre, W. J.; Radom, L.; Schleyer, P. R.; Pople, J. A. Ab Initio Molecular Orbital Theory; John Wiley \& Sons: New York, 1986.

(24) Pitzer, K. S.; Gwinn, W. J. Chem. Phys. 1942, 10, 428.

(25) Benson, S. W. Thermochemical Kinetics; Wiley-Interscience: New York, 1976.

(26) Westmoreland, P. R. Combust. Sci. Technol. 1992, 82, 151-168.

(27) Bozzelli, J. W.; Dean, A. M.; Ritter, E. R. Combust. Sci. Technol. 1991, 80, 63 .

(28) Gilbert, R. G.; Luther, K.; Troe, J. Ber. Bunsen-Ges. Phys. Chem. 1983, 87, 169

(29) Ochterski, J. W.; Petersson, G. A.; Montgomery, J. A., Jr. J. Chem. Phys. 1996, 104, 2598.

(30) Ayhens, Y. V.; Nicovich, J. M.; McKee, M. L.; Wine, P. H. J. Phys. Chem. A 1997, 101, 9382.

(31) Fulle, D.; Hamann, H. F.; Hippler, H.; Jänsch, C. P. Ber. BunsenGes. Phys. Chem. 1997, 101, 1435

(32) Canosa-Mas, C. E.; Dillon, T. J.; Sidebottom, H.; Thompson, K. C.; Wayne, R. P. Phys. Chem. Chem. Phys. 2001, 3, 542.

(33) Barat, R. B.; Bozzelli, J. W. J. Phys. Chem. 1992, 96, 2494. 